Article

\title{
A Validated HPLC-PDA-HRMS Method to Investigate the Biological Stability and Metabolism of Antiparasitic Triterpenic Esters
}

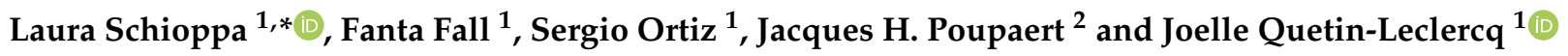 \\ 1 Pharmacognosy Laboratory, Louvain Drug Research Institute (LDRI), Université Catholique de \\ Louvain (UCLouvain), Avenue E. Mounier, B1 72.03, B-1200 Brussels, Belgium; fanta.fall@uclouvain.be (F.F.); \\ sergio.ortiz@uclouvain.be (S.O.); joelle.leclercq@uclouvain.be (J.Q.-L.) \\ 2 Medicinal Chemistry Research Group (CMFA), Louvain Drug Research Institute (LDRI), Université \\ Catholique de Louvain (UCLouvain), Avenue E. Mounier, B1 72.04, B-1200 Brussels, Belgium; \\ jacques.poupaert@uclouvain.be \\ * Correspondence: laura.schioppa@uclouvain.be
}

Citation: Schioppa, L.; Fall, F.; Ortiz, S.; Poupaert, J.H.; Quetin-Leclercq, J. A Validated HPLC-PDA-HRMS Method to Investigate the Biological Stability and Metabolism of Antiparasitic Triterpenic Esters. Molecules 2021, 26, 7154. https:// doi.org/10.3390/molecules26237154

Academic Editor: George Grant

Received: 26 October 2021

Accepted: 22 November 2021

Published: 26 November 2021

Publisher's Note: MDPI stays neutral with regard to jurisdictional claims in published maps and institutional affiliations.

Copyright: (c) 2021 by the authors. Licensee MDPI, Basel, Switzerland. This article is an open access article distributed under the terms and conditions of the Creative Commons Attribution (CC BY) license (https:/ / creativecommons.org/licenses/by/ $4.0 /)$.

\begin{abstract}
Pentacyclic triterpenes (PTs) are commonly found in medicinal plants with well-known antiparasitic effects. Previous research on C-3 and C-27 triterpenic esters showed effective and selective in vitro antiparasitic activities and in vivo effectiveness by parenteral routes. The aim of this study was to determine triterpenic esters' stability in different biological-like media and the main microsomal degradation products. An HPLC-PDA method was developed and validated to simultaneously analyze and quantify bioactive triterpenic esters in methanol (LOQ: 2.5 and $1.25-100 \mu \mathrm{g} / \mathrm{mL}$ ) and plasma (LOQ: 5-125 $\mathrm{gg} / \mathrm{mL}$ ). Overall, both triterpenic esters showed a stable profile in aqueous and buffered solutions as well as in entire plasma, suggesting gaining access to the ester function is difficult for plasma enzymes. Conversely, after $1 \mathrm{~h}, 30 \%$ esters degradation in acidic media was observed with potential different hydrolysis mechanisms. C-3 (15 and $150 \mu \mathrm{M})$ and C-27 esters (150 $\mu \mathrm{M})$ showed a relatively low hepatic microsomal metabolism $(<23 \%)$ after $1 \mathrm{~h}$, which was significantly higher in the lowest concentration of C-27 esters $(15 \mu \mathrm{M})(>40 \%$ degradation). Metabolic HPLC-PDAHRMS studies suggested hydrolysis, hydroxylation, dehydration, $O$-methylation, hydroxylation and/or the reduction of hydrolyzed derivatives, depending on the concentration and the position of the ester link. Further permeability and absorption studies are required to better define triterpenic esters pharmacokinetic and specific formulations designed to increase their oral bioavailability.
\end{abstract}

Keywords: triterpenes; stability; HPLC-PDA/MS; in vitro stability; metabolomics; parasitic infections

\section{Introduction}

Neglected tropical diseases (NTDs) account for $1 \%$ of the global disease burden, and more than 1.7 billion people require treatment for at least one NTD every year. For the fifth consecutive year, NTDs threatened more than one billion people despite the global implementation after 2008 [1]. Among protozoan infections, Human African Trypanosomiasis (HAT) caused by Trypanosoma brucei parasites still remains present in over 20 countries. In spite of registered cases dropping in 2015, an under-detection of cases should be considered during the reported incidence assessment [2]. Malaria, caused by Plasmodium protozoans, is the most widespread parasitic infection, with 229 million reported cases in 2019. A scale-up intervention series over the last decade helped to cut the mortality rate by $44 \%$ between 2010 and 2019 [3]. Even with the latest research and development improvement, the insufficient economic returns for developing new NTD drugs have strongly limited pharmaceutical industry R\&D, and so far, most infected people cannot afford for treatments even when they are available [4]. In this context and facing available treatment limitations as reduced efficacy, increased parasite resistance [5] and to aim to a potential large-scale distribution, new innovative oral therapies are crucially needed for such disease 
control or potential long-term elimination. Among promising natural compounds [6], triterpenoids are ubiquitous phytochemicals prevalent in the plant kingdom with significant pharmacological activities $[7,8]$. A potential treatment with triterpenes could allow for a multifactorial approach for targeting parasite growth and infection-induced symptoms for optimal disease control and resistance-development prevention. A mixture of eight coumaroyl/feruloyl triterpenic esters (8TTE) with selective in vitro and i.p. in vivo antimalarial activity was identified in Keetia leucantha twigs, supporting their traditional use and triterpenes interest in parasitology [9,10]. Moreover, recent hemi-synthesis of ursane C-3 triterpenic esters highlighted the in vitro and in vivo potential against Trypanosoma brucei of ursolic acid-3-O-phenyl propionate (UA-3-OPP) [11]. The present study aimed to investigate the stability of these promising antiparasitic triterpenic esters and their potential to target malaria and HAT infections. This is the first study on the biological stability and metabolism of these triterpenic esters in different physiological conditions to obtain crucial information to assess pharmacokinetic profiles and evaluate their potential for oral formulation and administration. To evaluate this stability, an HPLC-PDA-MS method was firstly developed and validated.

\section{Results and Discussion}

\subsection{Method Validation}

\subsubsection{Selectivity}

Selectivity and peak purity were assessed by retention times comparison and mass spectra analysis with reference standards (Supplementary Materials Figure S1). Three retention times corresponding to the beginning, the middle and the end of each peak were analyzed by HPLC-PDA-MS in ESI (-) to assess the molecular mass and spectra along the peak(s) (Supplementary Materials Figure S2). Molecular ion peaks at $\mathrm{m} / \mathrm{z}$ 587.41477 corresponded to [M - 1] $]^{-}$of UA-3-O-PP and $m / z 617.39047$ or 647.4013 to $[\mathrm{M}-1]^{-}$of coumaric or ferulic 8TTE derivatives, respectively. Method selectivity for plasma samples was assessed by HPLC-PDA showing no interfering peak at the 8TTE $(310 \mathrm{~nm})$, IS $(281 \mathrm{~nm})$ and UA-3-O-PP $(210 \mathrm{~nm})$ retention times in blank plasma.

\subsubsection{Response Function}

To demonstrate quantification reliability in the methanol and plasma, different regression models from calibration standards were analyzed [12]. For methanolic samples, linear regression was selected as the most adequate one, with $95 \%$ expectation tolerance intervals included inside the $\pm 20 \%$ acceptance limits for each concentration level of the validation standards (except the lowest one). For plasma samples, a square root transformation was performed to obtain the best calibration curve model. This total error concept simplifies decision making and reduces risks associated with procedure use [13].

\subsubsection{Trueness, Precision and Accuracy}

Trueness was calculated at each concentration level of the validation standards and expressed in relative bias (RB) $[14,15]$. For methanolic samples, the calculated relative bias for the 8TTE mixture and UA-3-O-PP were less than $7.24 \%$ and $5.05 \%$, respectively, showing the good trueness of the method (Table 1). Precision was evaluated intra-day (repeatability) and inter-day (intermediate precision) and expressed as relative standard deviations (RSD) $[13,16]$. Methanolic samples deviations were 4.78 and 2.18\% maximum for repeatability and 4.41 and $3.84 \%$ for the intermediate precision for 8TTE mixture and UA-3-O-PP, respectively (Table 1). Concerning plasma samples (Table 2), the relative bias of the 8TTE mixture and UA-3-O-PP were no more than 15.47 and $13.03 \%$, respectively. The repeatability was less than 2.66 and $2.89 \%$, and the intermediate precision values were 2.49 and $3.25 \%$ for 8 TTE mixture and UA-3-O-PP, respectively (Table 2). Repeatability and intermediate precision data show the excellent precision of the method for both compounds. All the trueness and precision results follow EMA guidelines criteria $(\leq 15 \%)$ [17]. Accuracy profiles, evaluating the sum of systematic and random errors (total error) $[12,14,15]$, 
indicated the relative upper and lower $95 \% \beta$-expectation tolerance limits were inside the acceptance limits set at $\pm 20 \%$ (Supplementary Materials Figure S3). All the validation results are presented in Tables 1 and 2.

Table 1. Validation results obtained for the quantification method of UA-3-O-PP and 8TTE in MeOH.

\begin{tabular}{|c|c|c|c|c|c|c|c|c|c|c|}
\hline \multicolumn{2}{|c|}{ Valid. Criteria } & \multicolumn{9}{|c|}{ Concentration Levels $(\mu \mathrm{g} / \mathrm{mL})$ for Methanolic Samples } \\
\hline & & \multicolumn{4}{|c|}{ UA-3-O-PP } & \multicolumn{5}{|c|}{ 8TTE } \\
\hline & & 2.5 & 10 & 37.5 & 100 & 1.25 & 2.5 & 37.5 & 75 & 100 \\
\hline \multirow{3}{*}{ Response function } & & \multicolumn{9}{|c|}{ Linear regression } \\
\hline & Calib. range & \multicolumn{4}{|c|}{4 points } & \multicolumn{5}{|c|}{5 points } \\
\hline & $\mu \mathrm{g} / \mathrm{mL}$ & \multicolumn{4}{|c|}{$2.5-100$} & \multicolumn{5}{|c|}{$1.25-100$} \\
\hline Trueness & Relative Bias (\%) & -1.87 & 5.05 & 0.06 & 0.51 & 7.24 & -2.80 & -4.14 & -2.38 & -1.58 \\
\hline \multirow{2}{*}{ Precision } & Repeatability (RSD $1 \%$ ) & 2.18 & 1.66 & 1.72 & 1.19 & 4.78 & 4.72 & 4.55 & 2.17 & 4.08 \\
\hline & $\begin{array}{c}\text { Intermediate precision } \\
\left(\mathrm{RSD}^{1} \%\right)\end{array}$ & 3.84 & 2.88 & 2.71 & 2.46 & 4.41 & 4.16 & 3.81 & 2.99 & 4.23 \\
\hline \multirow{2}{*}{ Accuracy } & \multirow{2}{*}{$\begin{array}{c}\text { (lower and uppertol. } \\
\text { Limits \%) }\end{array}$} & -15.59 & -5.26 & -8.34 & -8.35 & -3.27 & -12.63 & -13.23 & -11.54 & -12.18 \\
\hline & & 11.84 & 15.35 & 8.45 & 9.37 & 17.76 & 7.02 & 4.95 & 6.79 & 9.03 \\
\hline \multirow{3}{*}{ Linearity } & Slope & \multicolumn{4}{|c|}{1.003} & \multicolumn{5}{|c|}{0.982} \\
\hline & Int.pt & \multicolumn{4}{|c|}{0.122} & \multicolumn{5}{|c|}{-0.201} \\
\hline & $R^{2}$ & \multicolumn{4}{|c|}{0.999} & \multicolumn{5}{|c|}{0.997} \\
\hline
\end{tabular}

${ }^{1}$ RSD: Relative Standard Deviation.

Table 2. Validation results obtained for the quantification method of UA-3-O-PP and 8TTE in spiked plasma.

\begin{tabular}{|c|c|c|c|c|c|c|c|c|c|}
\hline \multicolumn{2}{|c|}{ Valid. Criteria } & \multicolumn{8}{|c|}{ Concentration Levels ${ }^{1}(\mu \mathrm{g} / \mathrm{mL})$ for Plasma Samples } \\
\hline & & \multicolumn{4}{|c|}{ UA-3-O-PP } & \multicolumn{4}{|c|}{ 8TTE } \\
\hline & & 5 & 25 & 50 & 100 & 5 & 25 & 50 & 100 \\
\hline \multirow{3}{*}{$\begin{array}{l}\text { Response } \\
\text { function }\end{array}$} & \multicolumn{9}{|c|}{ Linear regression } \\
\hline & Calib. range & \multicolumn{4}{|c|}{5 points } & \multicolumn{4}{|c|}{6 points } \\
\hline & $\mu \mathrm{g} / \mathrm{mL}$ & \multicolumn{4}{|c|}{$5-125$} & \multicolumn{4}{|c|}{$2.5-125$} \\
\hline Trueness & Relative Bias (\%) & -13.03 & -0.57 & -2.25 & -0.57 & 15.47 & 7.18 & -0.94 & 1.61 \\
\hline \multirow{2}{*}{ Precision } & Repeatability (RSD $2 \%)$ & 2.89 & 2.70 & 1.57 & 1.79 & 1.81 & 2.66 & 1.05 & 1.52 \\
\hline & $\begin{array}{c}\text { Intermediate precision } \\
\left(\mathrm{RSD}^{2} \%\right)\end{array}$ & 2.65 & 3.25 & 3.19 & 3.72 & 1.48 & 2.47 & 2.49 & 1.83 \\
\hline \multirow[t]{2}{*}{ Accuracy } & \multirow{2}{*}{$\begin{array}{c}\text { (lower and uppertol. } \\
\text { limits \%) }\end{array}$} & -19.35 & -9.67 & -13.74 & -13.97 & 11.85 & 1.28 & -9.97 & -3.26 \\
\hline & & -6.71 & 8.52 & 9.23 & 12.83 & 19.09 & 13.09 & 8.07 & 6.48 \\
\hline \multirow{3}{*}{ Linearity } & Slope & \multicolumn{4}{|c|}{0.998} & \multicolumn{4}{|c|}{1.004} \\
\hline & Int.pt & \multicolumn{4}{|c|}{-0.551} & \multicolumn{4}{|c|}{0.755} \\
\hline & $R^{2}$ & \multicolumn{4}{|c|}{0.998} & \multicolumn{4}{|c|}{0.999} \\
\hline
\end{tabular}

${ }^{1}$ Spiked Concentration; ${ }^{2}$ RSD: Relative Standard Deviation.

2.1.4. Detection and Quantification Limits

The limit of detection (LOD) is estimated for 8TTE mixture and UA-3-O-PP as 0.38 and $0.75 \mu \mathrm{g} / \mathrm{mL}$ in methanol and $1.5 \mu \mathrm{g} / \mathrm{mL}$ in plasma matrices, respectively, by the signal/noise method from the European Pharmacopoeia [18]. The limit of quantification was determined as the smallest tested concentration of the $95 \% \beta$-expectation tolerance limits remaining inside the $\pm 20 \%$ acceptance limits. It was then set at $1.25 \mu \mathrm{g} / \mathrm{mL}$ for $8 \mathrm{TTE}$ 
or $2.5 \mu \mathrm{g} / \mathrm{mL}$ for UA-3-O-PP in methanol and $5 \mu \mathrm{g} / \mathrm{mL}$ for both in plasma. Considering the two-fold concentration of plasma sample during treatment procedure, the method allows a precise quantification and detection in plasma from $2.5 \mu \mathrm{g} / \mathrm{mL}$.

\subsubsection{Uncertainty of Measurement}

To characterize values dispersion during routine analysis, the uncertainty of measurement was determined $[19,20]$. The expanded uncertainty is calculated by applying a coverage factor of $\mathrm{k}=2$ (corresponding to a $95 \%$ confidence interval around the estimated result). The maximum relative expanded uncertainty of the mixture of $8 \mathrm{TTE}$ is $9.8 \%$ while for UA-3-O-PP is $8.46 \%$, both inside the $\pm 20 \%$ acceptance limits. All estimated values for each validation standard concentration level are summarized in Table 3.

Table 3. Validation results obtained for the quantification method of UA-3-O-PP and 8TTE in MeOH.

\begin{tabular}{|c|c|c|c|c|c|c|}
\hline \multirow{2}{*}{$\begin{array}{c}\begin{array}{c}\text { Concentration } \\
\text { Level }\end{array} \\
(\mu \mathrm{g} / \mathrm{mL})\end{array}$} & \multicolumn{2}{|c|}{$\begin{array}{l}\text { Uncertainty } \\
(\mu \mathrm{g} / \mathrm{mL})\end{array}$} & \multicolumn{2}{|c|}{$\begin{array}{l}\text { Expanded Uncertainty } \\
(\mu \mathrm{g} / \mathrm{mL})\end{array}$} & \multicolumn{2}{|c|}{$\begin{array}{c}\text { Relative Expanded Uncertainty } \\
(\%)\end{array}$} \\
\hline & UA-3-O-PP & $8 \mathrm{TTE}$ & UA-3-O-PP & $8 \mathrm{TTE}$ & UA-3-O-PP & 8TTE \\
\hline \multicolumn{7}{|c|}{ Methanolic sample method } \\
\hline 1.25 & - & 0.061 & - & 0.122 & - & 9.780 \\
\hline 2.5 & 0.106 & 0.104 & 0.211 & 0.207 & 8.460 & 8.285 \\
\hline 10 & 0.340 & - & 0.680 & - & 6.801 & - \\
\hline 37.5 & 1.135 & 1.382 & 0.586 & 2.764 & 6.052 & 7.371 \\
\hline 75 & - & 2.417 & - & 4.834 & - & 6.445 \\
\hline 100 & 2.979 & 4.414 & 5.595 & 8.828 & 5.595 & 8.828 \\
\hline \multicolumn{7}{|c|}{ Plasma sample method } \\
\hline $5^{1}$ & 0.119 & 0.085 & 0.239 & 0.171 & 4.765 & 3.419 \\
\hline $25^{1}$ & 0.879 & 0.686 & 1.759 & 1.373 & 7.034 & 5.491 \\
\hline $50^{1}$ & 1.763 & 1.402 & 3.527 & 2.805 & 7.054 & 5.610 \\
\hline $100^{1}$ & 4.186 & 2.022 & 8.371 & 4.045 & 8.371 & 4.045 \\
\hline
\end{tabular}

${ }^{1}$ Spiked Concentration.

\subsubsection{Linearity}

To determine the linearity, the fitness of a regression line between back-calculated concentrations and exact concentrations was evaluated $[20,21]$. The estimated concentrations were plotted as a function of the introduced concentrations, and the built regression line was compared to the identity line $\mathrm{y}=\mathrm{x}$. For both methanolic and plasma samples, calculated slope values were close to 1 , supporting the good linearity of the method alongside the absolute $95 \% \beta$-expectation tolerance limits within the absolute acceptance limits $( \pm 20 \%$ ) (Supplementary Materials Figure S4).

\subsection{Stability Profiles Investigation}

Determination of the stability of new chemical entities is typically investigated in drug discovery or lead optimization [22]. The particular interest in the tested molecules is due to their aromatic ester functional groups in key positions, which induces increased antiplasmodial activity (natural esters) or decreases cytotoxicity (synthetic ester) compared to the corresponding triterpenic acids $[9,23]$. Furthermore, esterification can also lead to a bioavailability improvement, with a better potential for oral administration [24], a golden standard in the contest of tropical parasitic infections treatments. A stability profile investigation on these molecules was carried out in different environments and physiological conditions so as to mimic the $\mathrm{pH}$ environments of blood, stomach and intestine. A simple model-independent method was used, in which the percentage of remaining compound over time was determined by analyte and internal standard signals ratio and normalized to the value obtained at $t=0$. Results of the stability profiles are presented in Figure 1. All tested compounds, in aqueous and buffered conditions as well as entire plasma, were stable at both concentrations for $24 \mathrm{~h}$ (loss $<20 \%$, Figure $1 \mathrm{a}-\mathrm{c}$ ). 


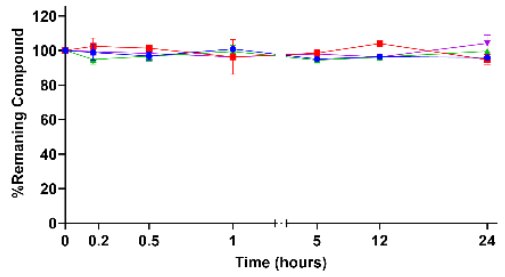

(a)

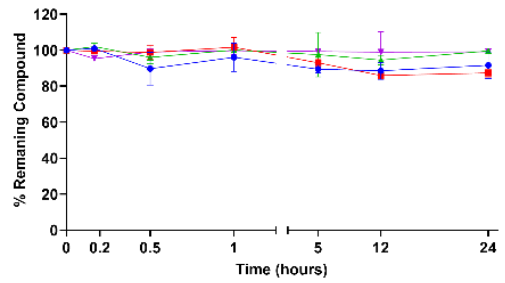

(c)

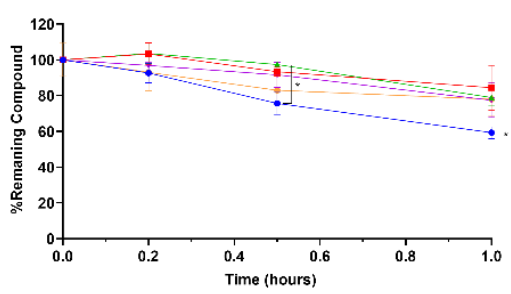

(e)

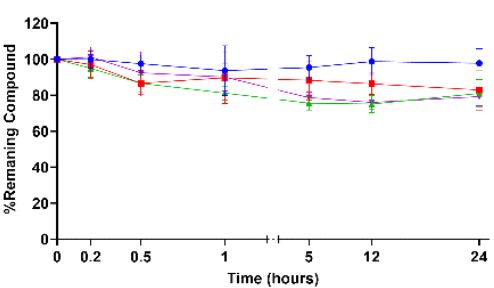

(b)

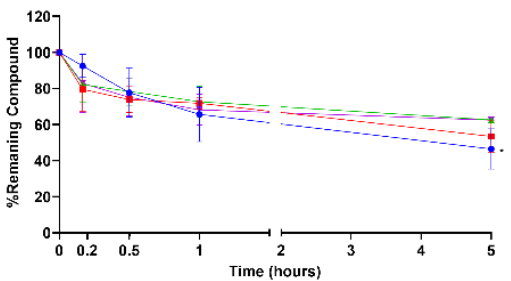

(d)

$$
\begin{aligned}
& \rightarrow 8 \text { TTE } 15 \mu \mathrm{M} \\
& -8 \text { TTE } 150 \mu \mathrm{M} \\
& \text { - UAOPP } 15 \mu \mathrm{M} \\
& \rightarrow \text { UAOPP } 150 \mu \mathrm{M} \\
& \rightarrow \text { Diclofenac } 10 \mu \mathrm{M}
\end{aligned}
$$

Figure 1. 8TTE, UA-3-O-PP and positive controls stability profiles in different simulated physiologic conditions at two different concentrations $(15 \mu \mathrm{M}-150 \mu \mathrm{M})$ : (a) water; (b) phosphate Buffer $0.1 \mathrm{M}$ pH 7.4; (c) entire plasma; (d) $\mathrm{HCl} \mathrm{pH} \mathrm{1.2;} \mathrm{(e)} \mathrm{pooled} \mathrm{male} \mathrm{mouse} \mathrm{microsomes.} \mathrm{Non-parametric}$ ANOVA analysis: $p<0.05$ (Kruskal-Wallis and Dunn's tests).

These results clearly indicate that near neutrality of the aqueous medium, the ester function remains acceptably stable, even for extended periods, showing that esters should be stable in fresh aqueous solutions but also in the intestine after administration. It is well established that ester hydrolysis is catalyzed by both acids and bases. In acidic medium, some degradation is actually observed (37-54\% degradation after $5 \mathrm{~h})$. Indeed, higher susceptibility to acidic medium ( $\mathrm{pH}$ 1.2) was exhibited for both esters with the natural ester's mixture being less stable after $5 \mathrm{~h}$ and significantly less stable for the lowest concentration (53.5\% degradation) (Figure $1 \mathrm{~d}$ ). At this $\mathrm{pH}$, the different stability of the $\mathrm{C}-3$ and C-27 triterpenic esters could be explained by different underlying hydrolysis mechanisms. While for the latter, a classic acid catalyzed ester hydrolysis (oxygen protonation followed by nucleophilic attack) applies, a potential SN1-like process might take place for C-3 esters. More in detail, when the carbonyl of the C-3 ester is protonated, the back strain produced by the neighboring gem-dimethyl group at the $\mathrm{C}-4$ position may induce the expulsion of the whole ester group by breaking the $\mathrm{C}(3)-\mathrm{O}$ bond and therefore forming a carbocation which subsequently recombines with a water molecule to regenerate ursolic acid. This process is specially facilitated when the $\mathrm{C}(3)-\mathrm{O}$ bond is longer than it would be in a less crowded ester. Further research is necessary to confirm this hypothesis. However, to prevent stomach degradation, different formulation approaches can be considered to improve their stability and bioavailability, e.g., gastro-resistant coating, cyclodextrin complexation, liposomes, nanoemulsions $[25,26]$. This study also aimed to evaluate stability and primary biotransformation(s) occurring in plasma and liver as they are linked to drug excretion and detoxification. According to literature, triterpenic acids as ursolic, oleanolic, asiatic and betulinic acids, are bound to plasma proteins for more than $95 \%$, leading to a low clearance and modifications of tertiary/secondary plasma proteins structures [27-29]. The obtained 
plasma results on triterpenic esters (Figure 2c) may also indicate a similar interaction inducing a low degradation rate and clearance. Indeed, the present plasma data did not show any behavioral difference related to the ester position on the triterpenic skeleton (C-3 or C-27). The metabolic (in)stability of the esters following incubation with mouse liver microsomes (Figure 2e) was also investigated. The degradation was significantly high for 8 TTE ( $>40 \%$ after $1 \mathrm{~h}$ ) at $15 \mu \mathrm{M}$, while it was more limited for the 3 other samples (max 22\% after $1 \mathrm{~h}$ ). It was observed a more stable behavior in C-3 esters compared to C-27 ones and a possible saturation for C-27 esters, but also a general slow metabolism in mouse CYP 450 enzymes. In vitro half-lives of $76.8 \mathrm{~min}$ and $264.3 \mathrm{~min}$ for 8TTE and UA-3-O-PP, respectively, were calculated. This is higher than non-esterified triterpenic acids as oleanolic acid, which showed a half-life between $\mathrm{t}_{1 / 2} 41.9$ and $52.7 \mathrm{~min}$ [28]. $\mathrm{T}_{1 / 2}$ is a common parameter in drugs screening, as it does not require metabolites identification but it presents some limitations as a first-order kinetic hypothesis. Current data allowed an in vitro intrinsic clearance $\left(C_{\text {intr }}\right)$ estimation assuming a linear kinetic. The in vitro estimated pharmacokinetic parameters are tabulated in Table 4. Improvement in half-life and pharmacokinetic parameters through a 3-O-esterification of oleanolic acid ( $3 \beta$-ester) was previously shown, which is in accordance with the presented findings [30]. The data obtained for tested esters are indicative of a medium and low mouse in vitro intrinsic clearance $(\mu \mathrm{L} / \mathrm{min} / \mathrm{mg}$ protein) for C-27 and C-3 esters, respectively, while the reference compound, diclofenac, also showed a low $\mathrm{C}_{\text {intr }}(9 \mu \mathrm{L} / \mathrm{min} / \mathrm{mg})$, yet this was higher than previously reported ( $5 \mu \mathrm{L} / \mathrm{min} / \mathrm{mg})$ [31]. Medium to low clearance drugs are more likely to be more bioavailable and better candidates for oral treatment compared to highly cleared compounds characterized by a shorter duration of action. As these in vitro intrinsic clearance's estimations do not consider constituents bound to microsomes medium, they are indicative but not sufficient to unambiguously evaluate a drug's clearance.
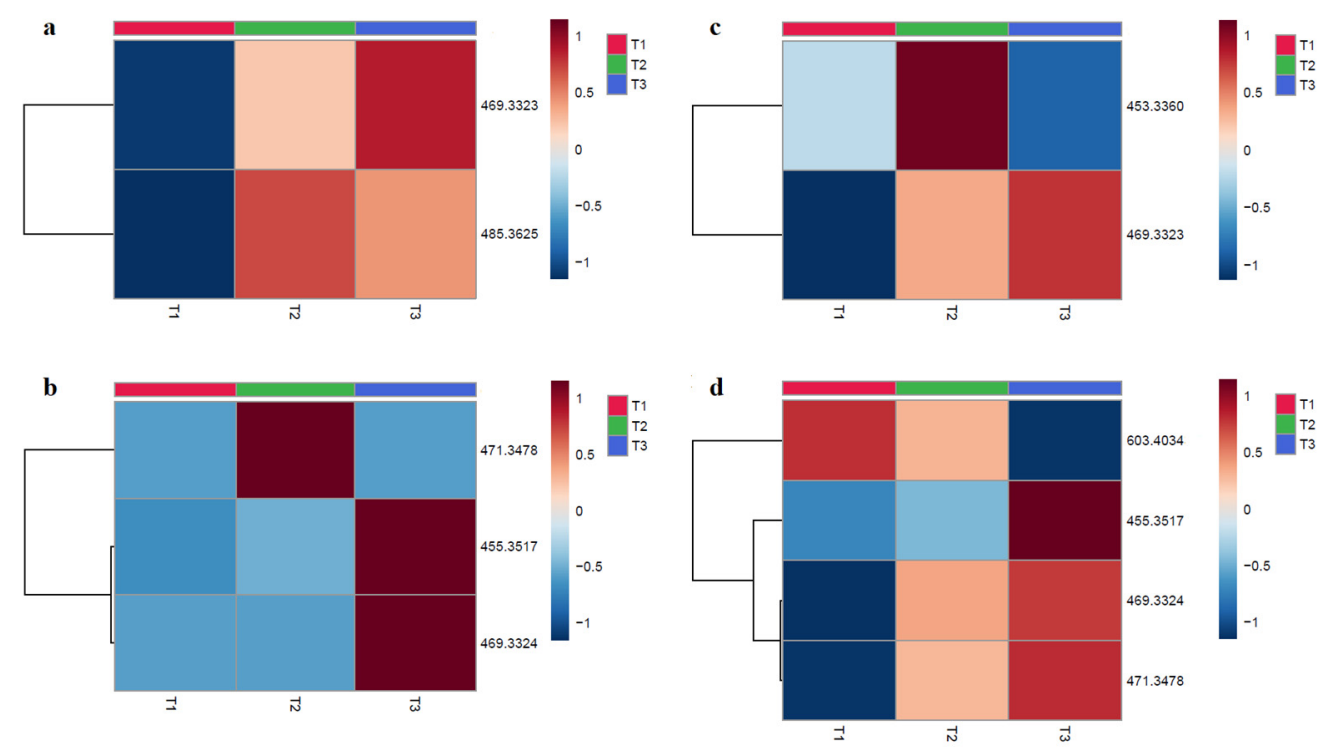

Figure 2. Heatmaps of molecular ions intensity in function of the tested timepoints for 8TTE and UA-3-O-PP. Each column represents an average of three samples $(n=3)$, and the rows represent a corresponding $\mathrm{m} / \mathrm{z}$. (red color = more expressed; blue color = less expressed): (a) 8TTE $15 \mu \mathrm{M}$; (b) 8TTE = $150 \mu \mathrm{M}$; (c) UA-3-O-PP $15 \mu \mathrm{M}$; (d) UA-3-O-PP $150 \mu \mathrm{M}$ (T1 = $0 \mathrm{~min}$, T2 = $30 \mathrm{~min}$; T3 = $60 \mathrm{~min}$ ). Analysis was performed using Euclidian distance method with ward clustering algorithm after normalization to sample median and Pareto scaling. 
Table 4. Elimination rate constant, half-life ( $\mathrm{min})$, in vitro intrinsic clearance ( $\mu \mathrm{L} \mathrm{min}^{-1} \mathrm{mg}^{-1}$ protein) calculated for tested triterpenic esters and diclofenac.

\begin{tabular}{cccc}
\hline & $\mathbf{K}_{\mathbf{l o s s}}\left(\mathbf{m i n}^{-1}\right)$ & $\mathbf{t}_{\mathbf{1 / 2}}(\mathbf{m i n})$ & $\mathbf{C l}$ Int $(\boldsymbol{\mu g} / \mathbf{m i n} / \mathbf{m g})$ \\
\hline 8TTE & 0.009 & 76.82 & 18.04 \\
UA-3-O-PP & 0.003 & 264.30 & 5.24 \\
Diclofenac & 0.004 & 153.25 & 9.04 \\
\hline
\end{tabular}

\subsection{Metabolites Analysis}

The metabolites analysis of tested compounds was performed after contact with male mouse pooled microsomes at two concentrations $(15 \mu \mathrm{M}$ and $150 \mu \mathrm{M})$. LC-PDA-HRMS analyses of treated compounds were made after different incubation times (T1 $=0 \mathrm{~min}$, $\mathrm{T} 2=30 \mathrm{~min}, \mathrm{~T} 3=60 \mathrm{~min}$ ) at both concentrations and showed a variation over time and in concentration. Potential metabolites are tabulated in Table 5. The metabolites structures are proposed with an identification level of 2 . The ions annotation in metabolomics was conducted at different levels; level 1 corresponds to the strongest degree of identification (two orthogonal analytical techniques applied with a chemical reference standard); level 2 is putatively annotated compounds (with public or commercial libraries); level 3 is putatively characterized compound classes; and level 4 corresponds to molecules without identification [32]. The proposed metabolites of the hemisynthetic ester UA-3-O-PP were potentially obtained by various phase- 1 metabolic transformations, such as hydrolysis (giving ursolic acid) and hydroxylation, with or without reduction in the pentacyclic skeleton. For the 8TTE mixture, we observed, in addition to hydrolysis, an aglycone dehydration, as was already observed for polyhydroxylated triterpenic acids such as maslinic, asiatic and madecassic acids $[33,34]$ and a reduction or a methylation of this aglycone. To confirm the proposed metabolites formation, further analysis is required with comparison to standards. The heatmaps represented in Figure 2 were obtained after normalization to sample median and display the intensity modification (formation or degradation) of the molecular ions of the proposed metabolites from HPLC-PDA-HRMS data. For the 8TTE mixture, hydrolysis with aglycone reduction $(\mathrm{m} / \mathrm{z} 469.3323)$ appeared to increase with time, while aglycone dehydration after hydrolysis $(m / z 453.3374)(150 \mu \mathrm{M})$ observed after $30 \mathrm{~min}$ appeared to be transitory. At lower concentration $(15 \mu \mathrm{M})$, an aglycone-O-methylation $(\mathrm{m} / \mathrm{z} 485.3625)$ after hydrolysis was observed after $30 \mathrm{~min}$ and slowly decreased over time, indicating the different partial metabolization between both concentrations (as previously observed for the degradation rate) (Figure 2a,b). Concerning UA-3-O-PP, Figure 2c, d shows a metabolite set formation over time at both concentrations. After $30 \mathrm{~min}$, all the aglycone formed by hydrolysis appeared hydroxylated $(\mathrm{m} / z$ 471.3479) and further reduced $(\mathrm{m} / \mathrm{z}$ 469.3324) for the next $30 \mathrm{~min}$ in parallel with a simple hydrolysis $(\mathrm{m} / z$ 453.3530), which was only also observed after $60 \mathrm{~min}$ at $150 \mu \mathrm{M}$. At this concentration, hydroxylation $(m / z 603.4034)$ of the unhydrolyzed molecule first occurred rapidly, with further hydrolysis later $(\mathrm{m} / \mathrm{z}$ 471.3479), while the proportion of hydroxylated and reduced aglycone $(\mathrm{m} / \mathrm{z}$ 469.3324) also increased with time. The heatmap allows the visualization of the metabolic evolution over time, but further exact metabolite quantifications are necessary. The formation of the unmodified aglycone was only observed for the synthetic ester, which can be considered to some extent as a prodrug for this triterpenic acid (ursolic acid) which also possesses good antiparasitic activity [23]. The aglycone of the natural esters was proven to be much less effective than the esters [9] and was only detected as aglycone metabolites after further metabolization, but the activity of these metabolites need further evaluation. Active metabolites' identification is also complementary for pharmacodynamic studies. Indeed, PTs display a large panel of pharmacological activities, suggesting a multi-target effect and a potential antiparasitic activity on different parasite life stages [35]. Currently, information on a precise mechanism of action for the tested triterpenic esters is lacking. Some UA derivatives have shown antiplasmodial activity on $\beta$-hematin formation or hemin degradation (via hydrogen peroxide or glutathione) [36], while antitrypanosomal 
activity of PTs can be explained by their known protein kinase $C$ inhibition [37]. Further research is needed to assess if the triterpenic esters studied here are active on these targets or might have other mode(s) of action(s).

Table 5. Identification, prediction level and metabolic reactions involved of the detected metabolites.

\begin{tabular}{|c|c|c|c|c|c|c|c|c|c|}
\hline \multirow{5}{*}{ 8TTE } & Conc. & $\begin{array}{c}\text { RT } \\
\text { (sec) }\end{array}$ & Mol. Ion & $\begin{array}{l}\text { Formula } \\
\text { (M) }\end{array}$ & $m / z \exp$ & $m / z$ thr & $\begin{array}{c}\Delta \\
\mathrm{ppm}\end{array}$ & ID vl & Reaction \\
\hline & \multirow[t]{2}{*}{$150 \mu \mathrm{M}$} & 1005.73 & {$[\mathrm{M}-1]^{-}$} & $\mathrm{C}_{30} \mathrm{H}_{46} \mathrm{O}_{3}$ & 453.3361 & 453.3374 & -2.8 & 2 & $\begin{array}{l}\text { Hydrolysis + } \\
\text { dehydration }\end{array}$ \\
\hline & & 884.76 & {$[\mathrm{M}-1]^{-}$} & $\mathrm{C}_{30} \mathrm{H}_{46} \mathrm{O}_{4}$ & 469.3323 & 469.3323 & 0 & 2 & $\begin{array}{l}\text { Hydrolysis + } \\
\text { Reduction }\end{array}$ \\
\hline & \multirow{2}{*}{$15 \mu \mathrm{M}$} & 884.76 & {$[\mathrm{M}-1]^{-}$} & $\mathrm{C}_{30} \mathrm{H}_{46} \mathrm{O}_{4}$ & 469.3323 & 469.3323 & 0 & 2 & Hydrolysis + Reduction \\
\hline & & 860.19 & {$[\mathrm{M}-1]^{-}$} & $\mathrm{C}_{31} \mathrm{H}_{50} \mathrm{O}_{4}$ & 485.3625 & 485.3631 & -1.2 & 2 & $\begin{array}{c}\text { Hydrolysis + } \\
\text { 0-Methylation }\end{array}$ \\
\hline \multirow{7}{*}{ UA-3-O-PP } & \multirow{4}{*}{$150 \mu \mathrm{M}$} & 951.46 & {$[\mathrm{M}-1]^{-}$} & $\mathrm{C}_{30} \mathrm{H}_{48} \mathrm{O}_{3}$ & 455.3518 & 455.3530 & 2.6 & 2 & Hydrolysis \\
\hline & & 869.94 & {$[\mathrm{M}-1]^{-}$} & $\mathrm{C}_{30} \mathrm{H}_{46} \mathrm{O}_{4}$ & 469.3324 & 469.3323 & 0.2 & 2 & $\begin{array}{l}\text { Hydrolysis + } \\
\text { Hydroxylation }+ \\
\text { Reduction }\end{array}$ \\
\hline & & 717.12 & {$[\mathrm{M}-1]^{-}$} & $\mathrm{C}_{30} \mathrm{H}_{48} \mathrm{O}_{4}$ & 471.3479 & 471.3479 & 0 & 2 & $\begin{array}{l}\text { Hydrolysis + } \\
\text { Hydroxylation }\end{array}$ \\
\hline & & 983.24 & {$[\mathrm{M}-1]^{-}$} & $\mathrm{C}_{39} \mathrm{H}_{56} \mathrm{O}_{5}$ & 603.4034 & 603.4055 & -3.5 & 2 & Hydroxylation \\
\hline & \multirow{3}{*}{$15 \mu \mathrm{M}$} & 951.46 & {$[\mathrm{M}-1]^{-}$} & $\mathrm{C}_{30} \mathrm{H}_{48} \mathrm{O}_{3}$ & 455.3518 & 455.3530 & 2.6 & 2 & Hydrolysis \\
\hline & & 869.94 & {$[\mathrm{M}-1]^{-}$} & $\mathrm{C}_{30} \mathrm{H}_{46} \mathrm{O}_{4}$ & 469.3324 & 469.3323 & 0.2 & 2 & $\begin{array}{l}\text { Hydrolysis }+ \\
\text { Hydroxylation }+ \\
\text { Reduction }\end{array}$ \\
\hline & & 717.12 & {$[\mathrm{M}-1]^{-}$} & $\mathrm{C}_{30} \mathrm{H}_{48} \mathrm{O}_{4}$ & 471.3479 & 471.3479 & 0 & 2 & $\begin{array}{l}\text { Hydrolysis + } \\
\text { Hydroxylation }\end{array}$ \\
\hline
\end{tabular}

\section{Materials and Methods}

All used organic solvents (VWR, Leuven, Belgium) were HPLC grade. Water was purified and deionized with a Milli-Q system manufactured by Millipore (Bedford, MA, USA). The estradiol valerate (purity 99\%) was purchased from Aca Pharma NV (Certa, Nazareth, Belgium) and used as internal standard. Procaine hydrochloride (purity $>97 \%$ ) and diclofenac sodium salt $(\geq 98 \%)$ were purchased from Sigma-Aldrich (Saint Louis, MO, USA) and Fagron, Belgium, respectively. Pooled male mouse liver microsomes, NADPH regenerating system and $0.5 \mathrm{M}$ potassium phosphate $(\mathrm{pH}=7.4)$ were obtained from Corning (Fischer Scientific, Tournai, Belgium) while human plasma was obtained from $\mathrm{CHU}$ patients (O-, Liège, Belgique). $\mathrm{HCl} 37 \%$ (Acros Organics) was used to prepare $\mathrm{pH} 1.2$ acidified water.

\subsection{Compound Isolation and Synthesis}

The mixture of 8TTE was isolated from the dichloromethane extract of Keetia leucantha twigs as described by Bero et al. [9] (Supplementary Materials Figure S5). UA-3-O-PP was hemi-synthetized as previously described from ursolic acid [11] (Supplementary Materials Figure S6). The compounds purity was assessed using an Accela HPLC-PDA system (Thermo Fisher Scientific Inc., Bremen, Germany) at 210 and $310 \mathrm{~nm}$ for hemi-synthetic $(>97 \%)$ and natural ( $>98 \%)$ compounds, respectively as described below. Twigs of Keetia leucantha (K. Krause) Bridson (syn. Lectronia leucantha Krause, Rubiaceae) were collected in Benin (Adjarra, Ouémé) in July 2011 and August 2012 and identified at the National Botanic Garden of Belgium in Meise (in comparison to voucher number BR0000005087129). 


\subsection{Standard solutions}

Methanolic calibration and validation standards were analyzed three times $(n=3)$ with three series of experiments $(\mathrm{k}=3)$ at four concentration levels $(\mathrm{m}=4)(100,50,10$ and $5 \mu \mathrm{g} / \mathrm{mL}$ for calibration standards and $75,32.5,10$ and 2.5 or $1.25 \mu \mathrm{g} / \mathrm{mL}$ for validation standards). For $8 \mathrm{TTE}$, the pure mixture ( $>98 \%$ purity by HPLC-PDA) was used as standard. For plasma studies, six working solutions $(\mathrm{m}=6)$ were prepared at $125,100,50,10,5$ and $2.5 \mu \mathrm{g} / \mathrm{mL}$ in methanol and spiked $(100 \mu \mathrm{L})$ in the blank biological matrix $(200 \mu \mathrm{L})$ as recommended by EMA guidelines [38]. A suitable internal standard (IS), estradiol valerate, was added during working solutions preparation from a stock solution of $1 \mathrm{mg} / \mathrm{mL}$ in methanol to obtain a constant $100 \mu \mathrm{g} / \mathrm{mL}$ concentration. The six concentration levels $(\mathrm{m}=6)$ of the calibration standards were analyzed in triplicate $(n=3)$ with 3 series of experiments $(\mathrm{k}=3)$. Validation standards were prepared in the same way with four working solutions concentration levels $(100,50,25$ and $5 \mu \mathrm{g} / \mathrm{mL}$ ). Final compound(s) concentrations in plasma were $0.8-41.6 \mu \mathrm{g} / \mathrm{mL}$. Three independent samples $(\mathrm{n}=3)$ at each concentration $(\mathrm{m}=4)$ were analyzed in duplicate for 3 series of experiments $(k=3)$.

\subsection{Plasma Samples}

An amount of $1 \mathrm{~mL}$ acetonitrile was added to $300 \mu \mathrm{L}$ samples that were submitted to 14,000 rpm centrifugation for $10 \mathrm{~min}$ at $4{ }^{\circ} \mathrm{C}$ (Eppendorf 5417R, Eppendorf AG, Hamburg, Germany). The supernatants were then evaporated with a CentriVap Benchtop Vacuum Concentrator, Labconco (Kansas City, MO, USA). The residues were dissolved in $100 \mu \mathrm{L}$ methanol, vortex-mixed, sonicated $1 \mathrm{~min}$ on ice, vortex-mixed and filtered before HPLCPDA analysis.

\subsection{HPLC-PDA- and HPLC-PDA-HRMS Analysis}

Samples were analyzed using an HPLC-PDA system consisting of a Thermo Accela pump, autosampler and photodiode array detector. The column used was a Poroshell $120 \mathrm{EC}-\mathrm{C} 18,100 \times 4.6 \mathrm{~mm}$ packed with $2.7 \mu \mathrm{m}$ particles. The flow rate was $0.8 \mathrm{~mL} / \mathrm{min}$ using a gradient solvent system: solvent $\mathrm{A}(35 \%)$ : $\mathrm{H}_{2} \mathrm{O}$, solvent $\mathrm{B}(30 \%)$ : acetonitrile, solvent C (35\%): methanol, for $4 \mathrm{~min}$, modified to reach solvent B $(65 \%)$ and solvent $C$ $(35 \%)$ at $15 \mathrm{~min}$, and then isocratic solvent system until $23 \mathrm{~min}$. Starting conditions were restored from min 25 until min 30. The injection volume was $20 \mu \mathrm{L}$, and autosampler and column temperatures were set at $4{ }^{\circ} \mathrm{C}$ and $25^{\circ} \mathrm{C}$, respectively. Signals were monitored at $210 \mathrm{~nm}$ for hemi-synthetic C-3 ester, $280 \mathrm{~nm}$ for the internal standard and $310 \mathrm{~nm}$ for natural C-27 esters. For HPLC-PDA-HRMS analysis, samples were analyzed in the same conditions using an HPLC-PDA-HRMS system consisting of a Thermo Accela pump, autosampler, photodiode array detector and Thermo Scientific LTQ orbitrap XL mass spectrometer. High-resolution mass spectra were measured with the ESI source in the negative mode. The following inlet conditions were applied: capillary voltage $-10 \mathrm{~V}$ $(-31 \mathrm{~V}$ for estradiol valerate), tube lens $-143.27 \mathrm{~V}(-118.27 \mathrm{~V}$ for estradiol valerate), ESI vaporizer temperature $275^{\circ} \mathrm{C}$, spray voltage $2.5 \mathrm{kV}$, sheath gas flow 15.00 a.u., auxiliary gas flow 15.00 a.u., sweep gas flow 15.00 a.u. Data acquisition and processing were performed with Xcalibur software. For metabolites analysis, raw data were converted into mzXML format with ProteoWizard [39] and then processed using XCMS software [40] into Worklow4Metabolomics 3.3 (W4M) [41]. CentWave was used for peak automatic detection and integration (peak picking, $\mathrm{ppm}=10$ ), while Camera was used for adducts and isotopes annotation [42]. Only peaks with twice the blank intensity were considered.

\subsection{Method Validation}

HPLC method was validated with three independent series of experiments. The same mobile phase was used all along with one series. Response function, linearity, selectivity, precision, trueness, accuracy, limit of detection (LOD) and limit of quantification (LOQ) and quantification range were investigated. The method selectivity was verified by HPLC-PDAHRMS on the equipment as described above by checking mass spectra at the beginning, 
middle and end of the peaks. For quantification in plasma, HPLC-PDA chromatograms obtained after sample preparation from blank plasma, and spiked plasma were compared at the maximum absorption wavelength of 8TTE $(310 \mathrm{~nm})$, IS $(281 \mathrm{~nm})$ and UA-3-O-PP $(210 \mathrm{~nm})$ to confirm the lack of interference peak in blank plasma at compounds of interest retention times. The validation of the presented bioanalytical method agrees with EMA guidelines defined by trueness and precision values lower than $15 \%$ and expressed with the relative bias (RB) and the relative standard deviation (RSD), respectively [43]. In addition, total error (sum of systematic and random error) was used as decision criteria for the validation process $[13,14,19-21,44]$. Statistical analyzes were performed using JMP v12 software. The acceptance limits $(\lambda)$ were set at $\pm 20 \%$, as is usually accepted for complex samples $[19,45]$. The probability of obtaining future results within these limits $(\beta)$ was set at $95 \%$.

\subsection{Stability Tests}

The compounds' stability was evaluated by measuring their disappearance with the validated HPLC-PDA method. The protocol for microsomal stability was adapted from both mammalian microsomes manufacturer guidelines and literature [30,46]. Compounds were dissolved in DMSO $(0.2 \%$ maximum final concentration) and tested at final concentrations of $15 \mu \mathrm{M}$ and $150 \mu \mathrm{M}$. Triterpenic esters were incubated at different conditions at $37^{\circ} \mathrm{C}$, away from light over time ( $1 \mathrm{~h}$ : microsomes; $5 \mathrm{~h}$ : acidic condition; $24 \mathrm{~h}$ : plasma, aqueous and buffered solutions). Acidic stability was investigated by incubation with $\mathrm{HCl}$ acidified water at $\mathrm{pH}=1.20 \pm 0.02$, assessed each day of the experiment by an Orion pH meter (Thermo Fisher Scientific Inc., Bremen, Germany). For microsomes stability, $1 \mathrm{mg} / \mathrm{mL}$ liver microsomes contained $100 \mathrm{mM}$ potassium phosphate $(\mathrm{pH} 7.4)$ and a NADPH regenerating system $\left(1.3 \mathrm{mM} \mathrm{NADP}^{+}, 3.3 \mathrm{mM}\right.$ magnesium chloride and glucose-6-phosphate, $0.4 \mathrm{U} / \mathrm{mL}$ glucose-6-phosphate dehydrogenase). Each microsomal experiment was compared with negative control (without NADPH) for each compound, and the eventual loss was subtracted to exclude sources of compound loss other than microsomal metabolism. For plasma stability studies, entire plasma was used with a protein content of $74.2 \mathrm{mg} / \mathrm{mL}$ (calculated with Folin reagent using bovine serum plasma as standard) [47] (Supplementary Materials Figure S7). Plasma esterase efficiency was assessed by quantifying the disappearance of a known control compound (procaine) and its metabolite appearance (PABA) over a $24 \mathrm{~h}$ period (Supplementary Materials Figure S8). For plasma and microsomes samples at each time point, acetonitrile (the same volume as the sample) was used for enzymes' inactivation or proteins' precipitation as stop solution, spiked with estradiol valerate as internal standard (IS) to reduce variability (final analyzed concentration of IS $=280.5 \mu \mathrm{M}=100 \mu \mathrm{g} / \mathrm{mL}$ ). The water samples buffered with $0.1 \mathrm{M}$ potassium phosphate $(\mathrm{pH} 7.4)$ were also treated with this stop solution, whereas $\mathrm{HCl}$ acidified water samples were neutralized by a $0.1 \mathrm{M} \mathrm{NaOH}$ solution with IS.

\subsection{Sampling and Data Analysis}

All samples were centrifuged at $14,000 \mathrm{rpm}$ for $10 \mathrm{~min}$ at $4{ }^{\circ} \mathrm{C}$, and supernatants were evaporated under vacuum with a CentriVap (Labconco). The residue was recovered in methanol (VWR, HPLC purity) and injected in HPLC-PDA. AUCs were normalized with IS ones and results are expressed according to values at $\mathrm{t}=0$ (considered as 100\% ester). For microsomes stability analysis, the remaining percentage versus the time was fit to a first decay function to estimate the rate constant of substrate loss $\left(\mathrm{K}_{\text {loss }}\right)$ using the GraphPad Prism software 8.4.2 [48]. The liver microsomal in vitro $t_{1 / 2}$, defined as the time required to reduce the concentration of a drug by $50 \%$, was calculated assuming the elimination was of first-order kinetics [49]. The in vitro intrinsic clearance $\left(C_{\text {int }}\right)$ was calculated as

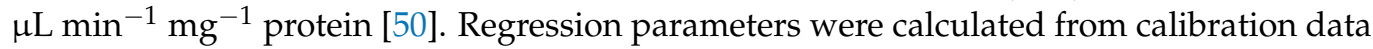
using Microsoft Excel and GraphPad Prism 8 software. In vitro data are presented as the mean \pm standard error and analyzed by GraphPad Prism 8 statistical software. 


\section{Conclusions}

Despite the known pentacyclic triterpenoids antiparasitic potential, the first pass effect and the low bioavailability are limiting their further development and application as orally administrated drugs. Many efforts have been made to improve the defects with chemically modified derivatives, but only a few pieces of research have investigated the pharmacokinetic data of triterpenic esters, mostly showing higher in vitro efficacy and selectivity. In this study, a unique HPLC-PDA-HRMS method was validated for the quantification of both C-27 and C-3 triterpenic esters. This method was found to be selective, linear, accurate, true and precise in methanolic samples and plasma for both investigated esters types. Preliminary in vitro investigations on these esters showed plasma and $\mathrm{pH} 7.4$ aqueous buffer stability, and also detected a certain degradation in a gastric environment and partial metabolism using mouse liver microsomes. Different hydrolysis mechanisms for the investigated esters were hypnotized. Metabolization was proposed to occur mainly via hydrolysis, hydroxylation, $\mathrm{O}$-methylation and reduction, but additional studies are required. Specific formulations should be considered to increase the bioactive triterpenic esters bioavailability and stability. Further pharmacokinetic and permeability studies are thus needed, along with mode of action(s) investigations, to further assess the potential of these molecules.

Supplementary Materials: The following are available online. Figure S1: HPLC-PDA chromatograms at different wavelengths of 8TTE, estradiol valerate (IS) and UA-3-O-PP analyzed by the validated method, Figure S2: Mass spectra of 8TTE triterpenic esters peaks (A-C) and UA-3-O-PP ester peak (D-F) taken at retention time corresponding to the beginning $(\mathrm{A}, \mathrm{D})$, the middle $(\mathrm{B}, \mathrm{E})$ and end $(\mathrm{C}, \mathrm{F})$ of triterpenic esters peaks. $\mathrm{Mc}=$ molecular ion $\left([\mathrm{M}-1]^{-}\right)$of natural $\mathrm{C} 27$ triterpenic esters with coumaric acid; $\mathrm{Mf}=$ molecular ion $\left([\mathrm{M}-1]^{-}\right)$of natural $\mathrm{C} 27$ triterpenic esters with ferulic acid; $\mathrm{M}=$ molecular ion $\left([\mathrm{M}-1]^{-}\right)$of hemi-synthetic $\mathrm{C} 3$ triterpenic ester, Figure S3: Accuracy profile of UA-3-O-PP in $\mathrm{MeOH}$ (A) and plasma (B) and of 8TTE in $\mathrm{MeOH}$ (C) and plasma (D) samples, respectively, with linear regression or after square root transformation. The steady line represents the relative bias, dashed lines indicate the $\beta$-expectation tolerance limits $(\beta=95 \%)$, and dotted lines represent the acceptance limits $( \pm 20 \%)$. The dots represent the relative back-calculated concentrations of the validation standards and are plotted according to their target concentration, Figure S4: Linearity profiles of UA-3-O-PP in $\mathrm{MeOH}$ (A) and plasma (B) and of 8TTE in $\mathrm{MeOH}$ (C) and plasma (D) samples, respectively. The dashed and dotted lined represent the $\beta$-expectations tolerance limits ( $\beta=95 \%)$ and acceptance limits $( \pm 20 \%)$. The plane line is the identity line $(y=x)$, Figure S5: Extraction and isolation process of the eight triterpenic esters mixture from the twigs of Keetia leucantha, Figure 6S: Ursolic acid -3-O- phenylpropionate synthesis scheme, Figure 7S: Schematic representation of Lowry assay, Figure 8S: Plasma stability data on entire human plasma for procaine with PABA formation.

Author Contributions: Conceptualization, L.S., F.F. and J.Q.-L.; methodology L.S. and F.F.; validation, L.S.; data curation, L.S., F.F., S.O. and J.Q.-L.; writing — original draft preparation, L.S., F.F.; writingreview and editing, L.S., F.F., S.O., J.H.P. and J.Q.-L. All authors have read and agreed to the published version of the manuscript.

Funding: Laura Schioppa is a research fellow at the Fonds de la Recherche Scientifique-(FNRS), and Fanta Fall has a post-doctoral grant in the frame of the METNATPAR PDR project (T.0092.20) funded by FNRS.

Acknowledgments: MS data were obtained at the MASSMET platform of UCLouvain. The authors want to thank Marie-France Hérent for her expertise and technical assistance.

Conflicts of Interest: The authors declare no conflict of interest.

Sample Availability: Samples of the compounds are not available from the authors.

\section{References}

1. Control of Neglected Tropical Diseases. Available online: https://www.who.int/teams/control-of-neglected-tropical-diseases (accessed on 10 February 2021).

2. Büscher, P.; Cecchi, G.; Jamonneau, V.; Priotto, G. Human African trypanosomiasis. Lancet 2017, 390, 2397-2409. [CrossRef] 
3. Prevention, C.-C. For D.C. and CDC-Malaria-Malaria Worldwide-Impact of Malaria. 2021. Available online: https://www. cdc.gov/malaria/malaria_worldwide/impact.html (accessed on 20 October 2021).

4. Conteh, L.; Engels, T.; Molyneux, D.H. Socioeconomic aspects of neglected tropical diseases. Lancet 2010, 375, 239-247. [CrossRef]

5. Ashley, E.A.; Dhorda, M.; Fairhurst, R.M.; Amaratunga, C.; Lim, P.; Suon, S.; Sreng, S.; Anderson, J.M.; Mao, S.; Sam, B.; et al. Spread of artemisinin resistance in Plasmodium falciparum malaria. N. Engl. J. Med. 2014, 371, 411-423. [CrossRef]

6. Newman, D.J.; Cragg, G.M. Natural Products as Sources of New Drugs from 1981 to 2014. J. Nat. Prod. 2016, 79, 629-661. [CrossRef] [PubMed]

7. Paduch, R.; Kandefer-Szerszen, M. Antitumor and Antiviral Activity of Pentacyclic Triterpenes. Mini. Rev. Org. Chem. 2014, 11, 262-268. [CrossRef]

8. Isah, M.B.; Ibrahim, M.A.; Mohammed, A.; Aliyu, A.B.; Masola, B.; Coetzer, T.H.T. A systematic review of pentacyclic triterpenes and their derivatives as chemotherapeutic agents against tropical parasitic diseases. Parasitology 2016, 143, 1219-1231. [CrossRef]

9. Bero, J.; Hérent, M.F.; Schmeda-Hirschmann, G.; Frédérich, M.; Quetin-Leclercq, J. In Vivo antimalarial activity of Keetia leucantha twigs extracts and in vitro antiplasmodial effect of their constituents. J. Ethnopharmacol. 2013, 149, 176-183. [CrossRef]

10. Beaufay, C.; Hérent, M.F.; Quetin-Leclercq, J.; Bero, J. In Vivo anti-malarial activity and toxicity studies of triterpenic esters isolated form Keetia leucantha and crude extracts. Malar. J. 2017, 16, 406. [CrossRef]

11. Schioppa, L.; Beaufay, D.C.; Bonneau, D.N.; Sanchez, D.M.; Girardi, D.C.; Leverrier, D.A.; Ortiz, D.S.; Palermo, P.J.; Poupaert, P.J.H.; Quetin-Leclercq, P.J. Design, Synthesis and Biological Activity of C3 Hemisynthetic Triterpenic Esters as Novel Antitrypanosomal Hits. ChemistryOpen 2021, 10, 896. [CrossRef]

12. Rozet, E.; Hubert, C.; Ceccato, A.; Dewé, W.; Ziemons, E.; Moonen, F.; Michail, K.; Wintersteiger, R.; Streel, B.; Boulanger, B.; et al. Using tolerance intervals in pre-study validation of analytical methods to predict in-study results. The fit-for-future-purpose concept. J. Chromatogr. A 2007, 1158, 126-137. [CrossRef]

13. Hubert, P.; Nguyen-Huu, J.J.; Boulanger, B.; Chapuzet, E.; Chiap, P.; Cohen, N.; Compagnon, P.A.; Dewé, W.; Feinberg, M.; Lallier, M.; et al. Harmonization of strategies for the validation of quantitative analytical procedures. A SFSTP proposal—Part II. J. Pharm. Biomed. Anal. 2007, 45, 70-81. [CrossRef] [PubMed]

14. Hubert, P.; Nguyen-Huu, J.J.; Boulanger, B.; Chapuzet, E.; Chiap, P.; Cohen, N.; Compagnon, P.A.; Dewé, W.; Feinberg, M.; Lallier, M.; et al. Harmonization of strategies for the validation of quantitative analytical procedures: A SFSTP proposal-Part I. J. Pharm. Biomed. Anal. 2004, 36, 579-586. [CrossRef] [PubMed]

15. Rozet, E.; Ceccato, A.; Hubert, C.; Ziemons, E.; Oprean, R.; Rudaz, S.; Boulanger, B.; Hubert, P. Analysis of recent pharmaceutical regulatory documents on analytical method validation. J. Chromatogr. A 2007, 1158, 111-125. [CrossRef]

16. Q2 (R1) Validation of Analytical Procedures: Text and Methodology I FDA. Available online: https://www.fda.gov/regulatory-i nformation/search-fda-guidance-documents / q2-r1-validation-analytical-procedures-text-and-methodology (accessed on 15 March 2021).

17. Medicines Agency, E. 2 ** Committee for Medicinal Products for Human Use (CHMP) Guideline on bioanalytical method validation; 1922. Available online: https:/ / www.ema.europa.eu/en/documents/scientific-guideline/draft-guideline-validat ion-bionanalytical-methods_en.pdf (accessed on 20 October 2021).

18. European Pharmacopoeia (Ph. Eur.) 10th Edition I EDQM-European Directorate for the Quality of Medicines. Available online: https:/ / www.edqm.eu/en/european-pharmacopoeia-ph-eur-10th-edition (accessed on 15 March 2021).

19. Lautié, E.; Rozet, E.; Hubert, P.; Quetin Leclercq, J. Quantification of rotenone in seeds of different species of yam bean (Pachyrhizus sp.) by a SPE HPLC-UV method. Food Chem. 2012, 131, 1531-1538. [CrossRef]

20. Rozet, E.; Marini, R.D.; Ziemons, E.; Boulanger, B.; Hubert, P. Advances in validation, risk and uncertainty assessment of bioanalytical methods. J. Pharm. Biomed. Anal. 2011, 55, 848-858. [CrossRef]

21. Hubert, P.; Nguyen-Huu, J.J.; Boulanger, B.; Chapuzet, E.; Cohen, N.; Compagnon, P.A.; Dewé, W.; Feinberg, M.; Laurentie, M.; Mercier, N.; et al. Harmonization of strategies for the validation of quantitative analytical procedures: A SFSTP proposal. Part IV. Examples of application. J. Pharm. Biomed. Anal. 2008, 48, 760-771. [CrossRef] [PubMed]

22. Di, L.; Kerns, E.H. Stability Challenges in Drug Discovery. Chem. Biodivers. 2009, 6, 1875-1886. [CrossRef] [PubMed]

23. Catteau, L.; Schioppa, L.; Beaufay, C.; Girardi, C.; Hérent, M.F.; Frédérich, M.; Quetin-Leclercq, J. Antiprotozoal activities of Triterpenic Acids and Ester Derivatives Isolated from the Leaves of Vitellaria paradoxa. Planta Med. 2021, 87, 860-867. [CrossRef]

24. Yu, Z.; Sun, W.; Peng, W.; Yu, R.; Li, G.; Jiang, T. Pharmacokinetics in vitro and in Vivo of Two Novel Prodrugs of Oleanolic Acid in Rats and Its Hepatoprotective Effects against Liver Injury Induced by $\mathrm{CCl}_{4}$. Mol. Pharm. 2016, 13, 1699-1710. [CrossRef]

25. Chand Gupta, A.; Bawankule, D.U.; Verma, A.K.; Shanker, K. Nanoemulsion preconcentrate of a pentacyclic triterpene for improved oral efficacy: Formulation design and in-vivo antimalarial activity. J. Drug Deliv. Sci. Technol. 2020, 57, 101734. [CrossRef]

26. Soica, C.; Trandafirescu, C.; Danciu, C.; Muntean, D.; Dehelean, C.; Simu, G. New improved drug delivery technologies for pentacyclic triterpenes: A review. Protein Pept. Lett. 2014, 21, 1137-1145. [CrossRef]

27. Furtado, N.A.J.C.; Pirson, L.; Edelberg, H.; Miranda, L.M.; Loira-Pastoriza, C.; Preat, V.; Larondelle, Y.; André, C.M. Pentacyclic triterpene bioavailability: An overview of in vitro and in vivo studies. Molecules 2017, 22, 400. [CrossRef] [PubMed]

28. Jeong, D.W.; Kim, Y.H.; Kim, H.H.; Ji, H.Y.; Yoo, S.D.; Choi, W.R.; Lee, S.M.; Han, C.K.; Lee, H.S. Dose-linear pharmacokinetics of oleanolic acid after intravenous and oral administration in rats. Biopharm. Drug Dispos. 2007, 28, 51-57. [CrossRef] [PubMed] 
29. Kartasasmita, R.; Musfiroh, I.; Muhtadi, A.; Ibrahim, S. Binding affinity of asiatic acid derivatives design against Inducible Nitric Oxide Synthase and ADMET Prediction ARTICLE INFO ABSTRACT. J. Appl. Pharm. Sci. 2014, 4, 75-80. [CrossRef]

30. Chen, D.; Huang, X.; Zhou, H.; Luo, H.; Wang, P.; Chang, Y.; He, X.; Ni, S.; Shen, Q.; Cao, G.; et al. Discovery of pentacyclic triterpene $3 \beta$-ester derivatives as a new class of cholesterol ester transfer protein inhibitors. Eur. J. Med. Chem. 2017, 139, 201-213. [CrossRef]

31. Mukkavilli, R.; Pinjari, J.; Patel, B.; Sengottuvelan, S.; Mondal, S.; Gadekar, A.; Verma, M.; Patel, J.; Pothuri, L.; Chandrashekar, G.; et al. In Vitro metabolism, disposition, preclinical pharmacokinetics and prediction of human pharmacokinetics of DNDI-VL-2098, a potential oral treatment for Visceral Leishmaniasis. Eur. J. Pharm. Sci. 2014, 65, 147-155. [CrossRef]

32. Viant, M.R.; Kurland, I.J.; Jones, M.R.; Dunn, W.B. How close are we to complete annotation of metabolomes? Curr. Opin. Chem. Biol. 2017, 36, 64-69. [CrossRef]

33. Sánchez-González, M.; Lozano-Mena, G.; Parra, A.; Juan, M.E.; Planas, J.M. Identification in rat plasma and urine by linear trap quadrupole-orbitrap mass spectrometry of the metabolites of maslinic acid, a triterpene from olives. J. Agric. Food Chem. 2015, 63, 1126-1132. [CrossRef]

34. Xia, B.; Bai, L.; Li, X.; Xiong, J.; Xu, P.; Xue, M. Structural Analysis of Metabolites of Asiatic Acid and Its Analogue Madecassic Acid in Zebrafish Using LC/IT-MSn. Molecules 2015, 20, 3001-3019. [CrossRef]

35. Moneriz, C.; Mestres, J.; Bautista, J.M.; Diez, A.; Puyet, A. Multi-targeted activity of maslinic acid as an antimalarial natural compound. FEBS J. 2011, 278, 2951-2961. [CrossRef]

36. Mullié, C.; Jonet, A.; Dassonville-Klimpt, A.; Gosmann, G.; Sonnet, P. Inhibitory effect of ursolic acid derivatives on hydrogen peroxide- and glutathione-mediated degradation of hemin: A possible additional mechanism of action for antimalarial activity. Exp. Parasitol. 2010, 125, 202-207. [CrossRef] [PubMed]

37. Maya, J.D.; Cassels, B.K.; Iturriaga-Vásquez, P.; Ferreira, J.; Faúndez, M.; Galanti, N.; Ferreira, A.; Morello, A. Mode of action of natural and synthetic drugs against Trypanosoma cruzi and their interaction with the mammalian host. Comp. Biochem. Physiol. Part A Mol. Integr. Physiol. 2007, 146, 601-620. [CrossRef]

38. Agency, E.M. Guideline on Bioanalytical Method Validation. 2011. Available online: https://www.ema.europa.eu/en/documen ts/scientific-guideline/guideline-bioanalytical-method-validation_en.pdf (accessed on 20 October 2021).

39. Kessner, D.; Chambers, M.; Burke, R.; Agus, D.; Mallick, P. ProteoWizard: Open source software for rapid proteomics tools development. Bioinformatics 2008, 24, 2534-2536. [CrossRef] [PubMed]

40. Smith, C.A.; Want, E.J.; O'Maille, G.; Abagyan, R.; Siuzdak, G. XCMS: Processing mass spectrometry data for metabolite profiling using nonlinear peak alignment, matching, and identification. Anal. Chem. 2006, 78, 779-787. [CrossRef]

41. Giacomoni, F.; Le Corguille, G.; Monsoor, M.; Landi, M.; Pericard, P.; Pétéra, M.; Duperier, C.; Tremblay-Franco, M.; Martin, J.-F.; Jacob, D. Workflow4Metabolomics: A collaborative research infrastructure for computational metabolomics. Bioinformatics 2015, 31, 1493-1495. [CrossRef]

42. Kuhl, C.; Tautenhahn, R.; Böttcher, C.; Larson, T.R.; Neumann, S. CAMERA: An integrated strategy for compound spectra extraction and annotation of liquid chromatography/mass spectrometry data sets. Anal. Chem. 2012, 84, 283-289. [CrossRef]

43. Rev 1 * EU Individual Case Safety Report (ICSR) 1 Implementation Guide Start of Public Consultation of First Version Individual Case Safety Reports (ICSRs) in Pharmacovigilance-Part 2: Human Pharmaceutical Reporting Requirements for ICSR (ISO 27953-2:2011) and the ICH E2B(R3) Implementation Guide. 2017. Available online: https:/ /ich.org/page/e2br3-individual-case -safety-report-icsr-specification-and-related-files (accessed on 20 October 2021).

44. Hubert, P.; Nguyen-Huu, J.J.; Boulanger, B.; Chapuzet, E.; Cohen, N.; Compagnon, P.A.; Dewé, W.; Feinberg, M.; Laurentie, M.; Mercier, N.; et al. Harmonization of strategies for the validation of quantitative analytical procedures. A SFSTP proposal-Part III. J. Pharm. Biomed. Anal. 2007, 45, 82-96. [CrossRef] [PubMed]

45. Rafamantanana, M.H.; Rozet, E.; Raoelison, G.E.; Cheuk, K.; Ratsimamanga, S.U.; Hubert, P.; Quetin-Leclercq, J. An improved HPLC-UV method for the simultaneous quantification of triterpenic glycosides and aglycones in leaves of Centella asiatica (L.) Urb (APIACEAE). J. Chromatogr. B 2009, 877, 2396-2402. [CrossRef]

46. Corning ${ }^{\circledR}$ Gentest ${ }^{\mathrm{TM}}$ Mouse (B6C3F1) Pooled Liver Microsomes, Male, 0.5 mL I B6C3F1, Male I Microsome Type I Life Sciences EU Other Consumer Site I Corning. Available online: https:/ / ecatalog.corning.com/life-sciences/b2c/EUOther/en/ADME-Tox-Res earch/Tissue-Fractions / Animal-Liver-Fractions / Animal-Liver-Tissue-Fraction-Products---Corning\%C2\%AE-GentestTM-An imal-Pooled-Liver-Microsomes-Mouse-Liver-Microsomes/p/452220 (accessed on 4 March 2021).

47. Lowry, O.H.; Rosebrough, N.J.; Farr, A.L.; Randall, R.J. Protein measurement with the Folin phenol reagent. J. Biol. Chem. 1951, 193, 265-275. [CrossRef]

48. Mohutsky, M.A.; Chien, J.Y.; Ring, B.J.; Wrighton, S.A. Predictions of the in vivo clearance of drugs from rate of loss using human liver microsomes for phase I and phase II biotransformations. Pharm. Res. 2006, 23, 654-662. [CrossRef]

49. Greenblatt, D.J. Elimination half-life of drugs: Value and limitations. Annu. Rev. Med. 1985, 36, 421-427. [CrossRef] [PubMed]

50. Bohnert, T.; Gan, L.L. In Vitro Experimental Models for Studying Drug Biotransformation. In Handbook of Metabolic Pathways of Xenobiotics; John Wiley \& Sons, Ltd.: Chichester, UK, 2013; pp. 1-61. 